\title{
AIDS decision threatens drugs trials
}

Sir - Your editorial, "Setting a bad example on AIDS", correctly points out the immediate consequences of the decision by South Africa's health minister, Nkosazana Zuma, not to fund the supply of the drug AZT for HIV-infected pregnant women (Nature 396, 603; 1998). But the impact goes far beyond the ultimate death of possibly thousands of infants who will be denied the potential benefit of AZT.

There are far-reaching implications which threaten the often difficult and complex proceedings that determine the design of clinical studies in developing countries; the commitment of pharmaceutical companies which evaluate therapies for developing countries; and the willingness of such companies to negotiate reduced prices for developing countries.

Current perinatal HIV prevention studies, aimed at reducing cost while preserving efficacy, have been designed with developing countries in mind. The availability of a drug following completion of a study in the host country is part of the ethical deliberations that are seriously considered before the approval of a clinical study. While an absolute guarantee is not required, the ethical review committee requires a certain degree of assurance that the host country and the pharmaceutical company will act in good faith to try to make a drug available.

Zuma's decision has escaped no one's attention. South Africa receives many grants from foreign agencies for clinical drug studies and hosts many drug studies sponsored by pharmaceutical companies. Pharmaceutical companies entered into negotiations with several developing countries to supply AZT at reduced cost to prevent perinatal HIV transmission. Zuma's decision may affect the willingness of scientists, funding agencies and companies to embrace trials in South Africa or other developing countries.

In addition, health ministers of poorer countries might use South Africa as an example to justify suspension of other public health measures, and pharmaceutical companies may begin to view drug evaluation in developing countries as too risky. The decision threatens to undermine the efforts of many of us who are trying to convince companies that they must provide approved drugs for evaluation in developing countries and support investigations of new drugs. Alienation of the academic community and pharmaceutical companies threatens to 'bite the hand' that has the potential to control the HIV epidemic.

It is not for scientists or funding agencies in developed countries to dictate what must be done in developing countries, nor for pharmaceutical companies to determine what drugs are necessarily best for a country with limited resources. However, if scientists, funding agencies and pharmaceutical companies respond to the desperate needs of developing countries and receive assurances that agreed commitments will be honoured, it is to no one's benefit to withdraw these commitments when there is a consensus that this will result in the unnecessary loss of thousands of lives.

Arthur J. Ammann

Global Strategies for HIV Prevention, 104 Dominican Drive, San Rafael,

California 94901, USA

\section{Money talks louder than research quality}

Sir - There would be few who would disagree with Gerard Vassiliou's comments about the exploitation of young scientists by ambitious group leaders in large 'factory' laboratories (Nature 396, 307; 1998). As a newcomer myself (PhD 1995) I certainly appreciate the problem. One of the most obvious reflections of this depressing trend is the almost total absence of single-author papers in leading journals.

Nowadays it seems one cannot do important research without joining a large group. What was not emphasized, however, was that this problem is an inevitable symptom of the academic reward system, which recognizes not just the quality and quantity of research, but also the associated funding. So researchers are hired and promoted partly on the operating budget and size of their group, and universities are ranked on the amount of research funds they attract. If two scientists in the same field produce work of equal quality and quantity, they should be rated identically. But the current reward system does not do this - the researcher who attracts more money is preferred.

The reward system is now so skewed that many people in less expensive fields (such as my area, animal morphology) feel compelled to apply for grants, not because they need the money to do research, but because they need to attract money to satisfy the powers that be.

Michael Lee

Department of Zoology, University of Queensland, St Lucia, Brisbane, Queensland 4072, Australia

\section{Lysenko took a dismal view ofMalthus}

Sir - The rejection of modern genetics by Stalin's biologist Trofim Lysenko is well known. Less well known is that he also rejected Thomas Malthus's insights into population biology which are so central to Darwinism. Roger Short ${ }^{1}$ notes the hostility of Marx and Engels to the "Dismal Theorem" of Malthus in which human population increases exponentially, subsistence increases arithmetically, and misery results. Lysenko went further and threw the baby out with the bathwater.

On 31 July 1948, Lysenko gave his opening address to the now notorious meeting of the Lenin Academy of Agricultural Sciences ${ }^{2}$. His first target was Malthus: "Many are still not clear about Darwin's error in transferring into his teaching Malthus' preposterous reactionary ideas on population.... Darwin himself was unable to fight free of the theoretical errors of which he was guilty. Today there is absolutely no justification for accepting the erroneous aspects of the Darwinian theory, those based on Malthus' theory of overpopulation with the inference of a struggle going on within species. And it is all the more inadmissible to represent those erroneous aspects as the cornerstone of Darwinism.”

What must it have felt like to hear the cornerstone of Darwinism dismissed as an error? It was the "classics of Marxism" that revealed this and other errors in Darwinism to Lysenko: "Biologists should always ponder these words of Engels, 'The entire Darwinian teaching on the struggle for existence merely transfers from society to the realm of living nature Hobbes' teaching on bellum omnium contra omnes and the bourgeois economic teaching on competition, along with Malthus' population theory.... The childishness of this procedure is obvious, and it is not worth while wasting words on it."'

Damning words, indeed. But five days later, one of Lysenko's fiercest opponents, B. M. Zavadovsky, launched a scathing attack on his intellectual impostures. $\mathrm{He}$ pointed out that this quotation was from a private letter Engels had written to a friend and he analysed the relevant sections of true Marxist classics: Engels' "Anti-Duhring" and the "Theory of Surplus Value" by Marx. 
The opinions of Marx and Engels are revealed as being rather more subtle. They accepted that human populations have the capacity for exponential increase, hence their delight that Darwin had disproved the "Dismal Theorem" by observing that 'subsistence' (that is, animals and plants) also has the capacity for exponential increase. Marx writes: "Darwin failed in his excellent work to see the fact that by discovering 'geometrical' progression in the animal and plant world, he was refuting the theory of Malthus. The Malthusian theory is based precisely on the point that he counterposes the geometrical progression of man to the 'arithmetical' progression of animals and plants."

Not only was Lysenko not a Darwinian, he was not even a Marxist, according to the analysis of Zavadovsky.

On 7 August 1948, Lysenko began his closing address by informing the conference that he had the endorsement of the Central Committee of the Communist Party for his views, and a letter that morning in Pravda confirmed this news. The debate was over. A third-rate scientist had risen to prominence through the backing of a ruthless dictator: how fortunate that such things no longer occur!

\section{Sean Nee}

Department of Zoology, University of Oxford South Parks Road, Oxford OX1 3PS, UK

1. Short, R. Nature 395, 456 (1998).

2. Opening address by Academician T. D. Lysenko in Proc. Lenin Acad. Agric. Sci. USSR, July 31-August 7, 1948 (Foreign Languages Publishing House, Moscow, 1949).

\section{Beauty and the} Bart Simpson effect

Sir - Douglas Yu and Glenn Shepard Jr have shown that, although it is widespread, the phenomenon that men find pictures of women more attractive if the image has a low waist-to-hip ratio is not culturally invariant ${ }^{1}$.

This aesthetic does not extend to Matsigenka men, isolated deep in Manu Park, Peru. These men prefer thick-waisted women. A good thing, since that apparently describes healthy young Matsigenka women. The authors make the reasonable suggestion that the apparent invariance of preferences in earlier studies "may have only reflected the pervasiveness of western media". Apparently, Matsigenka men do not share this aesthetic because "their degree of isolation is about as high as can be obtained today".

I found this result so interesting that I prepared a lecture on it for my behaviour class. I searched the World-Wide Web for pictures of the Matsigenka (also spelled 'Machiguenga') and found something ironic and amusing. At a site maintained by E. Russo, who collaborates with Shepard, there is a photo of a Matsigenka couple, Mateo and Aleja ${ }^{2}$. Mateo is holding an ocelot. Aleja is wearing a Bart Simpson Tshirt. The Matsigenka's isolation may be "about as high as can be obtained today", but they are not isolated enough to escape Bart Simpson. Luckily, it is not a Marge Simpson T-shirt. That would have suggested that the preference for thick-waisted women might also have been influenced by western media. Thomas Getty

Kellogg Biological Station, Hickory Corners, Michigan 49060, USA

Yu, D. W. \& Shepard, G. H. Jr Nature 396, 321-322 (1998) 2. http://www.montana.com/manu/village.html

\section{English versus Spanish in science evaluation}

Sir-Gianmarco Paris et al. ${ }^{1}$ consider how the frequency with which an article is cited is affected by its country of origin. They base their information on the Science Citation Index (SCI), an Institute of Scientific Information service comprising approximately 3,500 of the world's leading scientific and technical journals covering a broad range of disciplines. A parallel problem concerning this excellent database is seriously affecting some European and Latin American countries ${ }^{2}$. This is the misuse of the SCI in relation to language of publication in certain fields of work that are characterized by territoriality (for example, Earth science).

Major problems with its use can occur when: (1) publication in SCI journals is used as the only criterion for evaluating the scientific productivity of researchers and when it is used to confer prestige, stipends and even promotion; and (2) scientific tribunals pay more attention to the impact factor of the journal than to the quality of the scientific contribution.

Bearing in mind the difficulty of comparing quite similar CVs, the SCI-based evaluation provides an easier judgement procedure. But it is unfair to scientists from countries whose journals are poorly or not represented in the SCI. A good example of this biased analysis has recently been pointed out by the Centre for Scientific Information and Documentation (CINDOC) of the Spanish Consejo Superior de Investigaciones Cientificas (CSIC). The CINDOC is responsible for producing and distributing the ICYT database, a set of contributions in science and technology that has covered 500 Spanish bibliographic sources at an average annual rate of 6,500 items since 1979.

The CINDOC study covers a five-year period, surveying the productivity of the whole Spanish community of Earth scientists, and obtaining the opinion using a specially created, 27-point survey - of 383 of these researchers ${ }^{3}$. The design of the study allows it to indicate the extent of the language problem, as no Spanish-language Earth science journal is currently included in this SCI category.

The results obtained indicate that, whereas $73 \%$ of these scientists usually publish in both SCI and Spanish journals, most of their articles $(69 \%)$ are published in domestic journals. Therefore, the application of a solely SCI-based evaluation does not properly reflect their total scientific productivity and thus makes them unhappy with this evaluation procedure $58.5 \%$ of the whole, and more than $70 \%$ of researchers from universities and CSIC). When other databases besides the SCI and ICYT are included so as to give a wider range of Earth science journals (for example, GeoRef), the Spanish contribution to Earth science is found to be $7.3 \%$ of European production, occupying sixth place after the United Kingdom, France, Germany, Holland and Italy. The corresponding number derived from the SCI database is $5.6 \%$.

It is true that the lack of publication in SCI journals can indicate the low quality of some scientific contributions and/or the authors' inability to publish in high-quality international journals. But it is also true that scientific authorities should not disregard the idiosyncratic nature of some research fields, or the difficulty of publishing domestic work in international journals that demand topics be of "general interest". Thus, a frequent answer of journal editors is: "the paper is good but it would fit better in a local or regional journal". They apparently fail to realize that, due to the preponderance of English in science, many English papers are just as domestic as the Spanish ones. However, English-language journals that publish domestic science, such as J. Geol. Soc., Lond., get into the SCI, whereas the equivalent Spanish-language journals, such as Rev. Soc. Geol. Esp., do not.

If Europe wants a strongly united scientific community, it should define evaluation criteria that do not undervalue the quality of a publication simply because it is written in the 'wrong' language.

Jesús Rey-Rocha \& M. José Martín-Sempere Centre for Scientific Information and

Documentation (CINDOC), Consejo Superior de Investigaciones Científicas (CSIC), Joaquín Costa, 22. 28002 Madrid, Spain

\section{Fernando Lopez-Vera}

Department of Agricultural Chemistry, Geology and Geochemistry, Faculty of Sciences,

Universidad Autónoma de Madrid, Spain

\section{Jesus Martinez-Frias}

Departamento de Geología Museo Nacional de

Ciencias Naturales (CSIC), c/ José Gutierrez

Abascal, 28006 Madrid, Spain

1. Paris, G. et al. Nature 396, 210 (1998).

2. García-Guinea, J. Nature 379, 109 (1996)

3. Rey-Rocha, J. Thesis. Univ. Autónoma Madrid (1998). 